KATARZYNA JARKIEWICZ* - KRAKÓW

\title{
ZNAKI PAMIECI. O KOMEMORATYWNYM CHARAKTERZE OBRAZKA RELIGIJNEGO
}

Pojawienie się w XV wieku obrazka religijnego jako artefaktu osobistej pobożności przyniosło wielorakie zmiany $\mathrm{w}$ obyczajowości, $\mathrm{w}$ tym te związane $\mathrm{z}$ funeralnymi rytuałami ${ }^{1}$. Kultywowane od czasów starożytnych w zakonach mniszych zwyczaje pogrzebowe ulegną stopniowemu umasowieniu, co rozwinie produkcję żałobnych kart i wytworzy kulturę pamięci opartą na wierze w ,świętych obcowanie"2. U jej podłoża leży przekonanie, że umarli nadal żyją, mogą nas wspierać, ale również potrzebują pomocy celem pełnego uczestnictwa w zbawieniu. W związku z tym żyjący zobligowani są do modlitwy za zmarłych, wspominania ich przy okazji okolicznościowych nabożeństw i zamawiania intencjonalnych mszy św. ${ }^{3}$

\section{Rys historyczny}

Już we wczesnochrześcijańskich martyriach, kamienne inskrypcje zaopatrywano w pergaminowe kartki wspominkowe ${ }^{4}$. Ich obecność w iliryjskich klasztorach przyczyniła się do wytworzenia na przełomie VII i VIII wieku nowej

\footnotetext{
* Katarzyna Jarkiewicz - dr historii; adiunkt w Instytucie Kulturoznawstwa Akademii Ignatianum w Krakowie; e-mail: k.jarkiewicz.ign@gmail.com

${ }^{1}$ Por. J. Pirotte, Les images de devotion du XV siecle a nos jours. Introduction a l'etiude d'en „,media”, à: Imagiers de paradis. Images de piété populaire du XVe au XXe siècle, Bastogne-Bruxelles 1990, p. 11-13; M. Boisdequin, Les souvenirs mortuaires, à: Tamże, p. 179-188.

${ }^{2}$ Ch. Aka, Tot und vergessen? Sterbebilder als Zeugnis katholischen Totengedenkens, Detmold 1993, s. 18-19.

${ }^{3}$ F. Kusiak, Ze św. Franciszkiem z Asyżu poprzez śmierć cielesna do nieba na obrazkach z minionych wieków, Warszawa 2014, s. 25.

${ }^{4}$ Żałobne epitafia kończyły zwroty: have, anima candida (żegnaj nieskazitelna duszo), molliter ossa cubent (niechaj kości leżą wygodnie), terra sit super ossa levis (niechaj ziemia nie ciąży kościom), czy najczęściej sit tibi terra levis (niech ci ziemia lekką będzie). Szerzej: H. Lietzmann, Die Entstehung der Christlichen Liturgie nach den ältesten Quellen, „Vortrage der Bibliothek Warburg”, 5 (1929) s. 45-66.
} 
obyczajowości. Jej podstawą było sporządzanie pergaminowych rolek, które jako hagiograficzne informatory krążyły po europejskich opactwach od północno-zachodnich wybrzeży Wielkiej Brytanii po południowo-wschodnie Niemcy 5 . W dokumentach tych, zmarli w opinii świętości zakonnicy byli wspominani przez poszczególne wspólnoty, które na pierwotnie przekazany im tekst nanosiły nowe treści: modlitwy wstawiennicze, hymny pochwalne na cześć świętych patronów bądź ikonograficzne symbole. Najdłuższy zapis złożony z kilkudziesięciu połączonych ze sobą kart pergaminowych, na których swoje wpisy pozostawiło 800 klasztorów ma 30 m długości ${ }^{6}$. Od początku XIII wieku zwyczaj upowszechnia się wśród świeckich wspólnot franciszkańskich i dominikańskich. Rolki trafiają do kościołów parafialnych, których plebani zgadzają się modlić za zmarłych, często fundatorów i mecenasów, aby uzyskali w wyniku tych interwencji świętość porównywalną duszom zbawionych mnichów ${ }^{7}$. Wstawiennicze upamiętnienie staje się nieodzowne zwłaszcza, gdy przewrót reformacyjny podważy dotychczasową wiarę w odpuszczenie grzechów. Dla protestantów zbyteczne okażą się nawoływania do modlitwy poprzez karty pogrzebowe. Dusze zmarłych powstają ze snu dopiero w dniu Sądu Ostatecznego, który definitywnie rozstrzyga ich los. Nie ma czyśćca, gdzie grzesznicy mogliby pokutując czekać na zmartwychwstanie. W związku z tym fenomen komemoratywnych obrazków będzie de facto udziałem katolików ${ }^{8}$.

Pierwsze karty modlitewne za zmarłych pojawiają w 1. połowie XVII wieku w Holandii ${ }^{9}$. Miedziorytnicze odbitki tzw. bidprentjes zawierają podstawowe informacje o zmarłym oraz krótkie teksty modlitw poprzedzone zwrotem Bit voor de ziel (dla zbawienia duszy). Na wydrukowanym w 1638 roku w Amsterdamie obrazku pojawia się też symbolika pogrzebowa: skrzyżowane piszczele dają podstawę czaszce ${ }^{10}$. Barokowa ornamentyka zdaniem ks. Karela Van den Bergha zwraca uwagę na rolę wspólnot devotio moderna, które po przewrocie kalwiń-

${ }^{5}$ Por. R. Pernoud, Les Saints au Moyen Âge: la sainteté d'hier est-elle pour aujourd'hui?, Paris 1984, p 147-148.

${ }^{6}$ Por. J. Dufour, Les rouleaux et encycliques mortuaires de Catalogne (1008-1102), „Cahiers de civilisation médiévale" 20(1977), no 77, p. 13-14.

${ }^{7}$ W. Ollig, Zum frommen Gedenken... Ein papierenes Epitataph. Der Totenzettel im Wandel der Zeit, Fürstenfeldbruck 2009, s. 5-7.

${ }^{8}$ Kusiak, Ze św. Franciszkiem z Asyżu poprzez śmierć cielesna, s. 22.

${ }^{9}$ Najstarsze wykonywane ręcznie egzemplarze posiada Centralne Biuro Genealogii (CBGCentraal Bureau voor Genealogie) w Hadze, które dysponuje zdigitalizowanym zbiorem ponad miliona obrazków pogrzebowych. Równie imponujące kolekcje, liczące ponad 300.000 obiektów, posiada Albertinum w Nijmegen oraz Muzeum Ons' Lieve Heer op Solder, dawniej Amstelkring, w Amsterdamie. Egzemplarze flamandzkie z tego okresu zgromadził belgijski duchowny ks. Leopold Slosse. Jego zbiór miliona kart modlitewnych zakupiło miejskie archiwum w Kortrijk. Szerzej: J.A. J.M. Verspaandonk, Het hemels prentenboek. Devotie- en bidprentjes vanaf de 17 e eeuw tot het begin van de 20 e eeuw, Hilversum 1975, p. 5; E. Warlop, K. Maddens, De nieuwe Stadsbibliotheek en het Arrondissementsdepot van het Rijksarchief te Kortrijk, „Verslagen en mededelingen van de Leiegouw", 6 (1964) nr 1, p. 265-271.

${ }^{10}$ J.A. J.M. Verspaandonk, Het hemels prentenboek. Devotie- en bidprentjes vanaf de 17 e eeuw tot het begin van de 20e eeuw, Hilversum 1975, p. 7-10. 
skim przechowały w Holandii średniowieczne rytuały, dając nielicznej katolickiej społeczności sposobność zamanifestowania swych przekonań ${ }^{11}$. W duchu tym wykonano również kartę pamięci dla zmarłej w 1663 roku w klasztorze św. Bonifacego w Kolonii franciszkańskiej tercjarki Cathariny Balchem (fot.1). Odkryty w 2006 roku w Frechen Buschbell artefakt zawiera przywołanie w formie Jezus, Maryja, Franciszek, Elżbieta oraz werset informacyjny z potwierdzeniem otrzymania przez umierającą ostatnich sakramentów świętych. Tekst kończy wezwanie modlitewne oraz antyfona requiescat in pace ${ }^{12}$.

\section{Fot. 1. Obrazek komemoratywny Cathariny Balchem z 1663 roku}

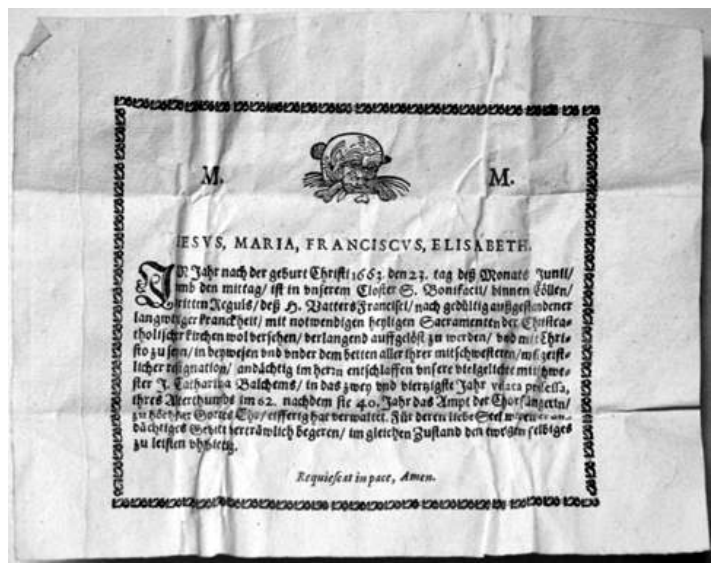

W najstarszym zbiorze niemieckich obrazków, zgromadzonym w bibliotece uniwersyteckiej w Würzburgu, znajduje się ponadto pochodząca z 1672 roku karta pamięci mnicha Franciszka Alberta z benedyktyńskiego opactwa Münsterschwarzach w Schwarzach am Main, która jako pierwsza podaje przyczynę śmierci. Wskazuje, że zmarły w młodym wieku zakonnik chorował na gruźlicę kręgosłupa i tym samym dostąpił poprzez cierpienie odpuszczenia grzechów oraz skrócenia czyśćcowych mąk ${ }^{13}$. W tym samym katalogu widnieje też obrazek z 1697 roku wydany po śmierci Marii Katarzyny Simon, w całości sporządzony w języku niemieckim, zamiast łaciny ${ }^{14}$. Tym samym następuje stopniowe upowszechnianie żałobnych kart wśród świeckich, najpierw w bractwach modlitewnych „dobrej śmierci", potem także w parafiach. Na terenie Dolnego Renu praktyka ta rozwinie się po 1783 roku $^{15}$. W 1820 roku obrazy pośmiertne pojawią się w Nadrenii ${ }^{16}$.

${ }^{11}$ Por. K. Van den Bergh, Bidprentjes in de zuidelijke Nederlanden, Brüssel 1975, p. 11-13.

${ }^{12} \mathrm{~W}$. Ollig, Zum frommen Gedenken ... Ein papierenes Epitataph. Der Totenzettel im Wandel der Zeit, Fürstenfeldbruck 2009, s. 3-4.

${ }^{13}$ Universitätsbibliothek Würzburg (UW), Sig 63/T 15.10, Totenzettel für Pater Franciscus A1bert aus dem Jahr 1672 .

${ }^{14}$ UW, Sig 63/T 15.2, Totenzettel für Frau Maria Catharina Simon aus dem Jahr 1697.

${ }^{15}$ Por. M.L. Carl, Totenzettel. Genealogische Quelle mit Geschichte, „Computergenealogie. Magazin für Familienforschung", 3 (2007) s. 17-18.

${ }^{16} \mathrm{Na}$ ich oznaczenie wprowadzono nazwę Totenbild(chen), Totenbrief, Trauerbild(chen) i Trauerzettel. 
Po 1840 roku rozpowszechnią się w Bawarii, Austrii i południowym Tyrolu ${ }^{17}$. W Szwajcarii tzw. Leidhelgeli zostaną po raz pierwszy wydane w Gryzonii w $1851 \mathrm{roku}^{18}$. Drukowane obrazki komemoratywne na szerszą skalę upowszechnią się we Francji dopiero w okresie II Cesarstwa, następnie dotrą do Włoch, Hiszpanii i Portugalii. Będą popularne w epoce wiktoriańskiej w Anglii i Irlandii. Potem przez Atlantyk przybędą do Stanów Zjednoczonych i Kanady. W nikłym stopniu będą obecne w środkowo-wschodniej Europie, gdzie tematyka śmierci zdominuje przede wszystkim artefakty patriotyczne ${ }^{19}$.

W nurcie tym będzie rozwijał się, zwłaszcza na terenie Niemiec, obrazek żołnierski tzw. Gefallenbildchen. Początki jego powstania wiążą się z dwoma pruskimi kampaniami wojennymi: z Austrią w 1866 roku i z Francją (1870-1871). Po raz pierwszy na masową skalę ginęli żołnierze poza granicami kraju, a uroczystości pogrzebowe miały charakter państwowy. Z uwagi na ogrom strat, utrudnione okazało się przeniesienie zwłok, co czyniło pochówki symbolicznymi ceremoniami. $\mathrm{Z}$ tej racji żałobnikom wręczano informatory donoszące o okolicznościach śmierci żołnierza oraz zachęcające do modlitw za niego. Pamiątkowe karty z owalnymi fotografiami zmarłego umieszczano w domach w tzw. świętym kącie (Herrgottswinkel) lub zawieszano na specjalnych tablicach pamięci w parafialnych kościołach, gdzie regularnie odbywały się modlitwy za poległych na wojnie ${ }^{20}$. Zwyczaj ten rozwinie się w okresie I i II wojny światowej (fot.2). Na komemoratywnych pamiątkach z okresu 1914-1918 będą znajdować się obok zdjęcia żołnierza w charakterystycznym dla jego oddziału uniformie, informacje o przebiegu jego służby, otrzymanych odznaczeniach oraz okolicznościach jego śmierci. Te sugestywne treści w stylu „zginął ugodzony bagnetem”, „został rozerwany granatem” lub ,zmarł zagazowany w okopach” zostaną usunięte na obrazkach żołnierskich po 1941 roku. W tym czasie fotografiom poległych w walce będzie towarzyszył rysunek ich grobów z brzozowymi krzyżami oraz hełmami. Żelazny Krzyż zastąpi swastyka i patetyczny tekst für Führer, Volk und Vaterland (za wodza, naród i ojczyznę). Treści religijne będą ograniczone do minimum, rzadko wzywając żałobników do modlitw czy innych form dewocyjnej pamięci ${ }^{21}$.

${ }^{17} \mathrm{Na}$ tym terenie panowało określenie Sterbebild(chen) lub Sterbezettel, Leichenzettel, Grabzettel, Leidbild i Leidbildchen. W Austrii używano szerszej formuły Parten lub Partezettel, która obejmowała obok kart pamięci także nekrologi.

${ }^{18}$ F. Aschwanden, W. Clauss, Urner Mundart-Wörterbuch, Altdorf 1982, s. 271; K. Imfeld, Obwaldner Mundart-Wörterbuch, Kriens 2000, s. 224. Szwajcarskie Towarzystwo Genealogiczne dysponuje zbiorem ponad 108.000 kart pogrzebowych. Państwowe archiwum w Lucernie zdigitalizowało ponad 18.000 żałobnych obrazków. Pokaźny zbiór leidhelgeli zawiera też Tal Museum w Engelbergu. Szerzej: Zum frommen Andenken. Leidhelgeli/Sterbebildchen in der Sammlung Dr. Edmund Müller, Hg. D. Wunderlin, Beromünster 2011; M. Christen, Die letzten Bilder: Tod, Erinnerung und Fotografie in der Zentralschweiz, Baden 2010.

${ }^{19}$ Szerzej: K. Jarkiewicz, Patriotyczne obrazki, „Posłaniec Serca Jezusowego”, 4 (2016) s. 54-56.

${ }^{20} \mathrm{~W}$. Ollig, Zum frommen Gedenken... Ein papierenes Epitataph. Der Totenzettel im Wandel der Zeit, Fürstenfeldbruck 2009, s. 15-17.

${ }^{21}$ H. Fischer, Rheinische Soldatentotenzettel, ,Heimatblätter des Rhein-Sieg-Kreises”, 79 (2011) s. 134-147. 


\section{Fot. 2. Obrazki żołnierskie z okresu I i II wojny światowej}
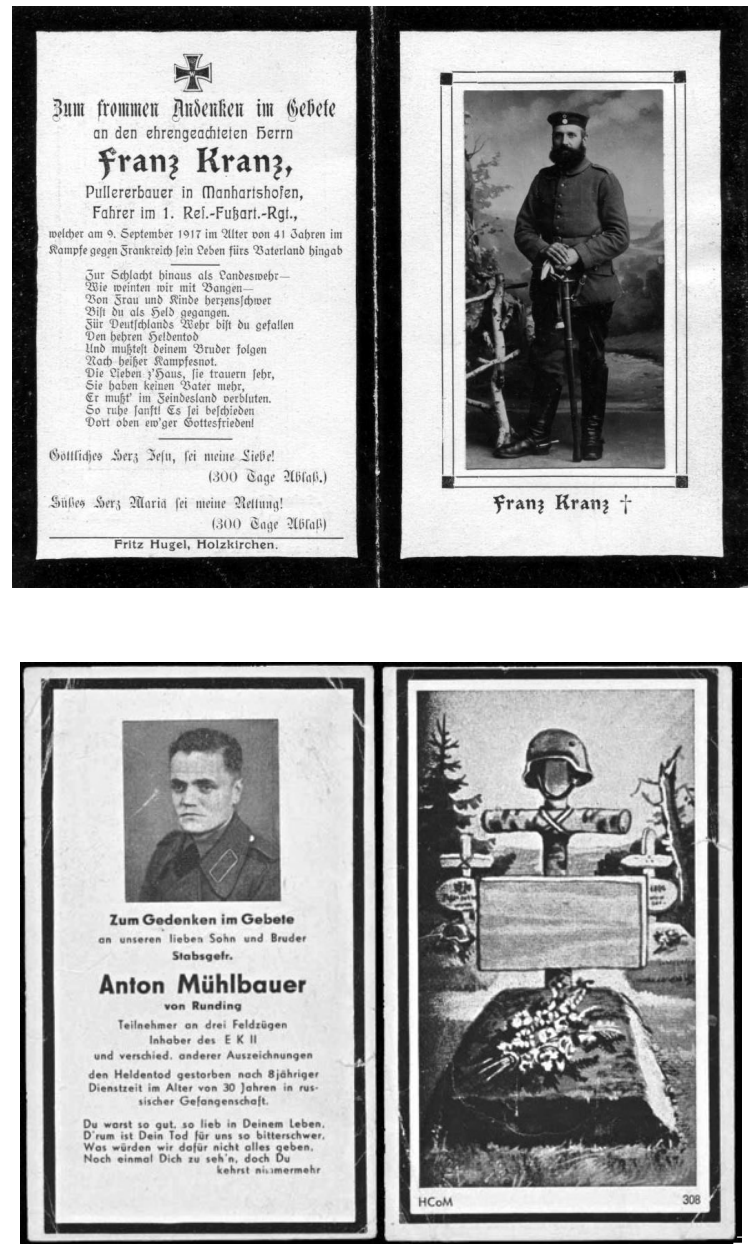

\section{Ikonografia i przekaz modlitewny}

Obrazek żałobny staje się towarem masowym po 1870 roku. Produkuje go większość ówczesnych wydawnictw dewocyjnych. Najwcześniej wprowadza katalogi funeralne drukarnia w München-Gladbach, założona przez Bernharda Kühlena w 1825 roku. Jej nowoczesne maszyny litograficzne nie tylko pozwalają na wykonanie po 1864 roku tzw. czarnych obwódek, ale także na dodatkowe zdobienia ich srebrnym albo złotym paseczkiem ${ }^{22}$. Popularność zyskują mniejsze ob-

${ }^{22}$ Szerzej: H.P. Mielke, Gott zur Ehre. Zum Bildprogramm des Kunstverlages B. Kühlen in Mönchengladbach, in: Volkskultur - Geschichte - Region: Festschrift für Wolfgang Brückner zum 60. Geburstag (Quellen und Forschungen zur europäischen Ethnologie, Bd. 7), Hg. D. Harmening, E. Wimmer, Würzburg 1990, s. 475- 492. 
razki. Początkowo dominowały artefakty liczące od $10 \mathrm{~cm}$ do $40 \mathrm{~cm}$ wysokości, które łatwo można było przypiąć szpilkami do ścian. Po 1880 roku żałobne druczki przybierają kształt prostokąta o wymiarach 4,5 cm długości i $8,5 \mathrm{~cm}$ szerokości lub od $5 \mathrm{~cm}$ do $14 \mathrm{~cm}$ wysokości, dostosowanego do wielkości modlitewnika, który ze sobą zabierano celem odmówienia intencjonalnych modlitw podczas nabożeństw żałobnych i wspominkowych ${ }^{23}$. Niejednokrotnie przekładano je do portfeli, aby towarzyszyły odpustom i pielgrzymkom do lokalnych sanktuariów. Następnie przez dziesiątki lat żałobne druczki przechowywano w biurkach i komodach, tak że utrwalił się w Niemczech zwyczaj modlitw za tych „którzy leżą w szufladach" ${ }^{24}$.

Przeobrażeniom uległa również grafika religijna. Rozbudowane treści ikonograficzne stosowała wytwórnia Josepha Benzigera w Einsiedeln w Szwajcarii oraz norymberskie wydawnictwo Serz ${ }^{25}$. Głównym motywem na obrazkach żałobnych staje się męka Chrystusa, sceny zarówno z drogi krzyżowej, jak i agonii na Górze Oliwnej (fot.3). Popularny okaże się temat ukrzyżowania wsparty cytatami z Ewangelii (m.in. „Boże, mój Boże, czemuś mnie opuścił”, „Wykonało się!"). Wizerunki samotnego, przybitego do krzyża Zbawiciela na tle Jerozolimy będą korespondowały z obrazami klęczącej pod krzyżem Marii Magdaleny bądź stojącej obok św. Jana, Madonny. Przedstawienia będą nawiązywać do znanych dzieł Dürera, Grünewalda, van Dycka czy Velazqueza, ale także będą powstawały na zamówienie konkretnych wydawnictw dewocyjnych. Obrazki żałobne będą projektowali m.in. specjalizujący się w stalorytach nazareńczycy: Franz Ittenbach i Johann Fredrich Overbeck. Oprócz przedstawień ukrzyżowania popularność zyskają sceny biczowania i ukoronowania, które będą otaczane srebrnym obramowaniem z napisem „Oto człowiek”. Motyw ozdobionej koroną cierniową głowy Chrystusa zwykle będzie nawiązywał do obrazów Guida Reniego. Rzadziej będzie występował temat Jezusa niosącego krzyż, upadającego pod jego naporem czy napominajacego płaczące niewiasty. Sam krzyż w postaci symbolu śmierci i cierpienia ulegnie stylizacji, podobnie jak sceny zmartwychwstania czy wniebowstąpienia, które dodatkowo będą wzmacniane obrazem otaczających Chrystusa dusz. Popularność zyskają też wzorowane na obrazach Carla Dolciego przedstawienia Matki Bożej Bolesnej. Dolorosę z przebitym sercem będą malować również Dolabella, El Greco, Memling, Murillo czy Tycjan. W celu ukojenia żalu po stracie ukochanych osób żałobnicy będą sięgać po wyobrażenia cierpiącej Maryi, która trzyma na kolanach umęczone ciało Chrystusa lub obrazy św. Józefa na łożu śmierci (fot. 4). Za patronów dobrego odejście będą uchodzić ponadto św. Barbara, św. Dyzma czyli Dobry Łotr, św. Jan Chrzciciel, św. Jan Ewangelista, św. Juda

${ }^{23}$ Por. M.L. Carl, Totenzettel. Genealogische Quelle mit Geschichte, „Computergenealogie. Magazin für Familienforschung", 3 (2007) s. 19-21.

${ }^{24} \mathrm{Ch}$. Aka, Tot und vergessen? Sterbebilder als Zeugnis katholischen Totengedenkens, Detmold 1993, s. 20.

${ }^{25}$ M.T. Engels, Das kleine Andachtsbild. Prägedrucke und Stanzspitzenbilder des. 19. Jahrhunderts, Recklinghausen 1983, s. 28; S. Seifert, Totenbildchen, in: Memento Mori - Gedenke des Todes - Erinnerung hilft. Totenbildchen. Sammlung Pfarrer Joachim Meckler, Hg. S. Seifert, J. Meckler, Schöntal Bieringen 1993, s. 10-11. 
Tadeusz czy św. Maria Magdalena, choć oczywiście w powszechnym użyciu będą także przedstawienia chrzcielnych patronów lub innych ważnych wspomożycieli, np. św. Michała Archanioła. Wizerunki Aniołów Stróżów pojawią się natomiast na obrazkach żałobnych dzieci² ${ }^{26}$.

\section{Fot. 3. Ikonografia pasyjna}
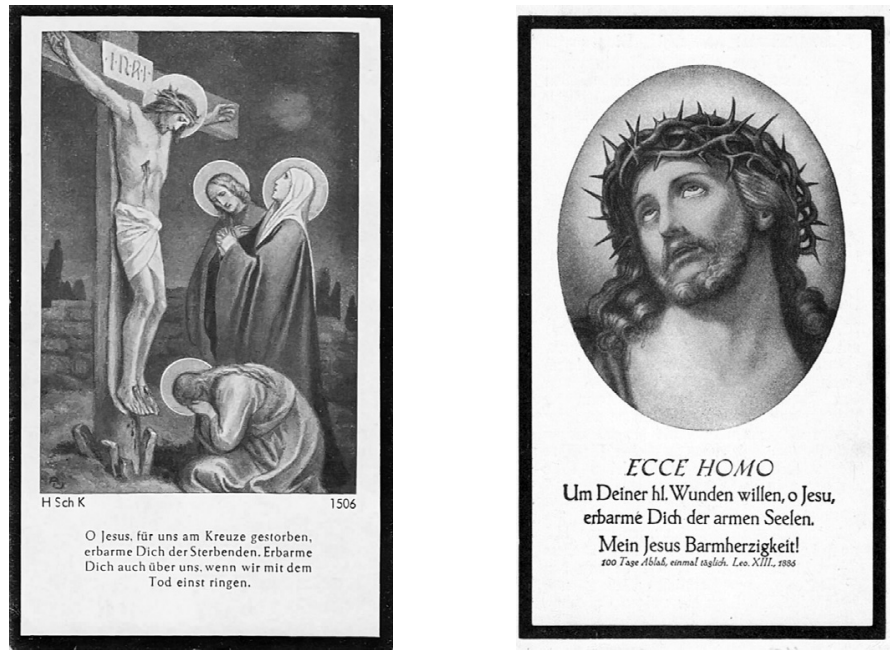

Fot. 4. Ikonografia maryjna
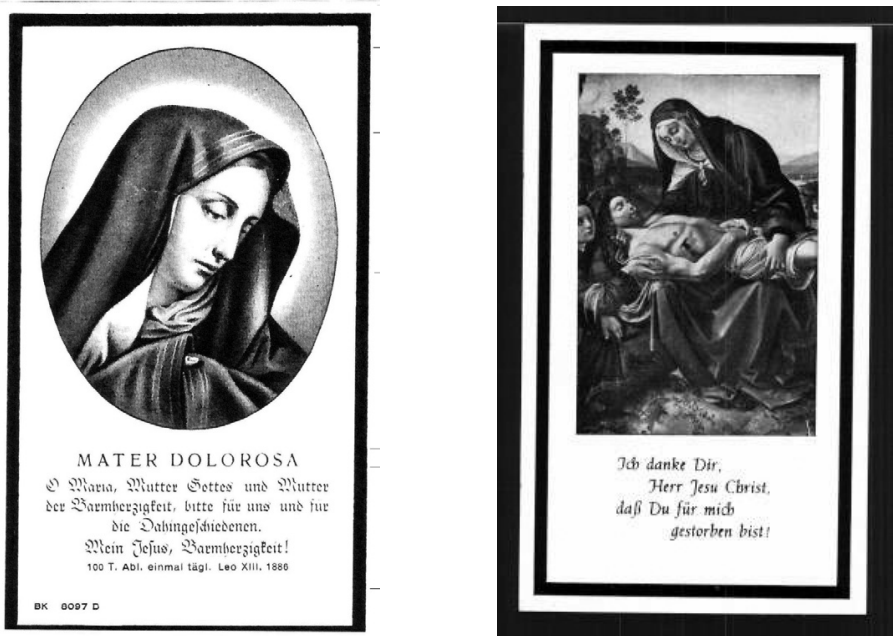

${ }^{26}$ Szerzej: B. Schwering, Totenzettel. Zur Geschichte eines sepukralkulturellen Brauchrequisits, „Rheinisches Jahrbuch für Volkskunde”, 34 (2001/2002) s. 49-66. 
Po 1870 roku na kartach pamięci zatriumfują fotografie zmarłych osób ${ }^{27}$. Początkowo będą wycinane z nekrologów i naklejane na obrazku, a po 1855 roku drukowane wprost $\mathrm{z}$ płyty bądź kliszy fotograficznej. Zmarli będą stylizowani, ukazywani w otoczeniu zniczy, krzyży, urn, kolumn i płyt pamiątkowych ${ }^{28}$. Podczas I wojny światowej popularnością będą się cieszyć wizerunki ,upadłych bohaterów": fotografie zmarłych żołnierzy, którzy z pola walki będą przenoszeni do domu przez Jezusa bądź Maryję. Wzrośnie też liczba prezentacji zmarłych w trumnach, często udekorowanych i przystrojonych odświętnie, gdyż wkraczają w nowy świat. Towarzyszą im ukochane przedmioty kultu: obrazki, medaliki, różańce, ale także symbole społecznej pozycji: książki czy klucze. Zmarły w 1935 roku Józef Piłsudski został na obrazku przedstawiony w trumnie, gdy ściska w dłoni wizerunek Matki Boskiej Ostrobramskiej ${ }^{29}$. Po 1960 roku nastąpią kolejne zmiany. Religijna ikonografia praktycznie zaniknie z wyjątkiem niektórych wizerunków maryjnych, jak obraz Czarnej Madonny z bawarskiego sanktuarium Altötting. Wiarę w „świętych obcowanie” będą symbolizować złożone do modlitwy ręce Dürera (Betende Hände, Praying Hands) bądź samotny krzyż w górach. Dominować będą zdjęcia jesiennych krajobrazów, wschodów i zachodów słońca, widoków nieba z tęczą. Kolorowym fotografiom zmarłych będą towarzyszyć wirtualne hologramy odsyłające do sieciowych cmentarzy (fot.5) ${ }^{30}$.

\section{Fot. 5. Współczesny obrazek komemoratywny}
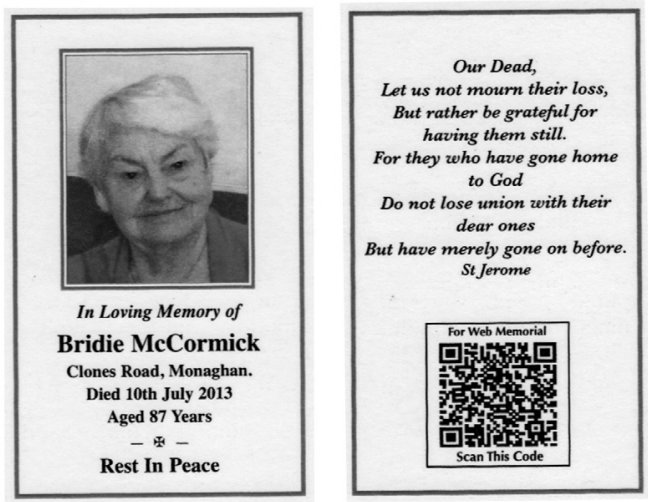

${ }^{27}$ Pierwszy w Niemczech obrazek z fotografią zmarłej właścicielki ziemskiej pochodzi z 1846 roku. Por. F. Demmel, Das Sterbebildchen- die letzte Visitenkarte, in: Das Mühlrad. Beiträge zur Geschichte des Inn- und Isengaues. Band XXXIII, Mühldorf 1991, s. 159-166.

${ }^{28}$ Por. H. Gärtner., Andachtsbildchen: Kleinode privater Frömmigkeitskultur, München 2004, s. 11-13.

${ }^{29}$ S. Rayski, Genjusz niepodległości, Lwów 1935, s. 14.

${ }^{30}$ Por. Ł. Kapralska, A. Maksymowicz, Śmierć w Internecie, w: Od robotnika do internauty. W kierunku społeczeństwa informacyjnego, red. A. Siwik, L.H. Haber, Kraków 2008, s. 310-311. 
Z ikonografią będą współgrały treści informacyjne o dużym zakresie dowolności. W zasadzie karty pamięci odpowiadają zapisom metrykalnym z ksiąg parafialnych. Podają datę i miejsce śmierci zmarłego, jego wiek w chwili zgonu, czasem pozycję społeczno-zawodową ${ }^{31}$. $Z$ uwagi na troskę żałobników o zbawienie zmarłego, obrazki przekazują informacje na temat przyjętych sakramentów świętych, zwłaszcza wiatyku. W tym aspekcie niemowlętom i malutkim dzieciom nie drukowano typowych pośmiertnych artefaktów, gdyż nie miały możliwości zgrzeszyć. Istotne bardziej było przekonanie, czy uzyskały pociechę duchową w godzinie śmierci, aby „powiększyć grono aniołków”, jak przytomnie zaznaczano, wskazując na brak konieczności modlitw skracających takim zmarłym męki czyśćcowe ${ }^{32}$. W latach 1860-1885 w Niemczech zamieszczano na obrazkach żałobnych nazwisko rodowe, zawód i miejsce w hierarchii społecznej. U osób awansujących stosowano zapis wskazujący na kolejne szczeble społecznego i ekonomicznego sukcesu: od najemnika po prebendarza, od czeladnika po mistrza. Zdegradowanym wskazywano ich aktualną pozycję w chwili śmierci, dołączając zapewnienie o godziwym charakterze ich profesji, np. jedyny w powiecie gołębiarz, pierwszy w przysiółku stróż nocny. W przypadku kobiet podawano zawód męża, co miało zapobiec licznym pomyłkom w tożsamości zmarłych. W Bawarii używano przy tym nieformalnych zwrotów odnoszących się społecznego statusu (,cnotliwa dziewica”, ,szlachetna matrona”, „nieutulona w żalu wdowa”) bądź ekonomicznej pozycji („właścicielka Gasthofu”, „pani na Eisenbergu"). Dbano zwłaszcza o skrupulatne wskazanie daty zgonu. Nie były rzadkością teksty w stylu: „śmierć przecięła jego nić życia w trzecim kwadransie po drugiej” lub ,z wybiciem nieszpornej godziny odeszła od nas”, co wobec częstych procesów spadkowych ułatwiało żałobnikom dochodzenie roszczeń z tytułu poniesionych wydatków pogrzebowych. Do 1880 roku podawano także przyczynę zgonu. Po tej dacie ograniczano się do informacji, że zmarły odszedł po długich cierpieniach lub skonał niespodziewanie. Nazwy chorób skrupulatnie wskazywano, stosując nawet medyczną terminologię jak tuberculosis na oznaczenie gruźlicy czy infarctus opisujący zawał. Ekscytujące były zwłaszcza tragiczne zgony. Obrazki donosiły więc, że zmarły został zabity przez uderzenie pioruna lub utonął wraz z wozem i koniem podczas przeprawy przez rzekę. Wobec samobójców nie stosowano pociechy modlitewnej, stąd praktycznie brak żałobnych druczków o tej treści. Na niektórych obrazkach zaznaczona została aprobata Kościoła (con licencia Eclestiastica) lub zgoda miejscowego biskupa (imprimatur), zwłaszcza odnośnie modlitewnych praktyk co do przyznawanych z tego tytułu zmarłym odpustów ${ }^{33}$.

${ }^{31}$ E.M. Ciregna, Museums of Death, in: Encyclopedia of Death and the Human Experience, ed. C.D. Bryant, D.L. Peck, Los Angeles-London 2009, s. 765.

${ }^{32}$ Kusiak, Ze św. Franciszkiem z Asyżu poprzez śmierć cielesna, s. 65.

${ }^{33}$ Por. H. Fischer, Zum frommen Andenken. Biographisches Erzählen auf Totenzetteln, „Rheinisches Jahrbuch für Volkskunde", 34 (2001/2002) s. 69; B.F. Lesaar, Totenzettel - Sterbebildchen als Hilfsquellen für die Familienforschung, „Genealogie - Deutsche Zeitschrift für Familienkunde", 4 (2008) s. 289-296; B. Schwering, Totenzettel. Zur Geschichte eines sepukralkulturellen Brauchrequisits, „Rheinisches Jahrbuch für Volkskunde”, 34 ( 2001/2002) s. 49-66. 
Najistotniejszą treścią żałobnych druczków była modlitwa. Zawsze rozpoczynała ją apostrofa skierowana do Świętej Rodziny w postaci zamieszczonych u góry obrazka imion Jezusa, Maryi i Józefa bądź samych inicjałów „J.M.J”. Niekiedy pojawiały się też inne osoby: patroni bractw religijnych lub świeci lokalni. Po wezwaniu Świętej Rodziny umieszczano sekwencję zwaną aforyzmem lub sentencją. Budowały ją cytaty z Pisma Świętego bądź wypowiedzi Ojców Kościoła, papieży i świętych. Gotowe sentencje podawali wydawcy obrazków, ale żałobnicy mogli sami wskazać tekst istotny dla zmarłego. Franciszek Kusiak zwraca uwagę, że tercjarze często cytowali Pieśń stoneczna św. Franciszka jako modlitwę doniosłą dla swej religijności. W tekście znajdujemy choćby takie pouczenia: „Biada tym, którzy umierają w grzechach śmiertelnych. Błogosławieni ci, których [śmierć] zastanie w Twojej najświętszej woli, albowiem śmierć druga nie wyrządzi im krzywdy"34. Tym samym utrwalany był przekaz o nieuchronności śmierci i boskiej sprawiedliwości, która pozwala wyrównać ziemskie krzywdy i przywrócić ludziom nadzieję na właściwy sąd. Po sentencji następowała prośba do Boga o przebaczenie zmarłym wszelkich win, darowanie grzechów i otwarcie bram niebios. Modlitwę wstawienniczą kończyła prośba: „Wieczne odpoczywanie racz jej/jemu dać Panie”. Zamieszczano też wezwanie do odmawiania „Ojcze nasz”, „Wyznania wiary” czy modlitwy „Anioł Pański”. Pod obrazkiem umieszczano napis zwykle pogrubiony „Niech spoczywa w pokoju” w formie inicjałów „R.I.P.” bądź łacińskiego napisu Requiescat in pace ${ }^{35}$. Na ziemiach polskich używano też formy „Pokój jej/jego duszy” w układzie „P.J.D.”.

W początkach XX wieku stopniowo zanikała rozbudowana forma modlitewna. Pozostaje wezwanie do osiągnięcia przez zmarłego wiecznego odpoczynku. Cytaty z Biblii ustępują wersetom aktualnych literackich bestsellerów, fragmentom popularnych pieśni, a niekiedy nawet przemówień sławnych polityków. Uznanie zyskuje dedykowany zmarłemu wiersz. Laicyzacja żałobnych druczków pogłębia się po II wojnie światowej. Zanika czarna obwódka obrazka, pojawiają się kolorowe fotografie zmarłych prezentowanych w otoczeniu bliskich osób i podczas wykonywania ulubionych zajęć. Zdjęcia się laminuje i przytwierdza do magnesu, co pozwala komemoratywne pamiątki dowolnie przenosić na tablice pamięci umieszczane nie tylko w kościołach, ale również w zakładach pracy. Po 1970 roku treść żałobnych druczków umieszcza się na winylowych kartach z efektami trójwymiarowymi. Obecnie komemoratywne pamiątki dystrybuuje się wśród żałobników za pomocą Internetu lub poprzez wiadomości SMS ${ }^{36}$.

${ }^{34}$ Kusiak, Ze św. Franciszkiem z Asyżu poprzez śmierć cielesna, s. 29.

${ }^{35}$ Por. W. Ollig, Zum frommen Gedenken... Ein papierenes Epitataph. Der Totenzettel im Wandel der Zeit, Fürstenfeldbruck 2009, s. 17-21; D. Wunderlin, Das Leidhelgeli als Informationsträger und Erinnerungshilfe, in: Zum frommen Andenken. Leidhelgeli/Sterbebildchen in der Sammlung Dr. Edmund Müller, Hg. D. Wunderlin, Beromünster 2011, s. 35-49.

${ }^{36}$ K. Jarkiewicz, Sakralność i profaniczność obrazka religijnego. Wokót problemów oddziatywania Kościoła na sferę wytwórczości dewocyjnej, w: Ponowoczesne przestrzenie oddziaływań wychowawczo-formacyjnych Kościoła i ,ziemie niczyje”, red. R. Jasnos, E. Miśkowiec, Kraków 2015, s. 266. 


\section{Podsumowanie}

O komemoratywnym charakterze obrazka religijnego świadczą zarówno naniesione na niego wyobrażenia ikonograficzne, jak i treść. Upamiętnieniu podlega nasza wiedza o zmarłym, jego życiowych dokonaniach i duchowych potrzebach, które zaspakajamy poprzez modlitwę i wspominkowe nabożeństwa. Tym samym żałobny artefakt podtrzymuje pamięć o zmarłym odwołując się do religijnych przesłanek ,świętych obcowania”, choć proces ten coraz częściej jest kształtowany przez laickie wyobrażenia. Kontemplowanie śmierci i wspominanie przenoszone jest do sieci i na nowe narzędzia komunikacji masowej. Stosunek do zmarłych kształtowany jest nie tyle poprzez wiarę w świat pozagrobowy, co w związku z więzią emocjonalną i społeczną towarzyszącą naszym relacjom. Tym samym komemoratywne pamiątki stają się gadżetami funeralnej kultury, nie są zaś symbolami świata duchowego. $\mathrm{O}$ ich rozwoju bądź zaniku będzie decydowało społeczne zapotrzebowanie.

Słowa kluczowe: kultura pamięci; kultura śmierci; obrazek religijny; żałobny artefakt; ikonografia żałobna; modlitwa za zmarłych

\section{BIBLIOGRAFIA}

\section{Źródła}

Universitätsbibliothek Würzburg (UW)

Sig 63/T 15.10, Totenzettel für Pater Franciscus Albert aus dem Jahr 1672.

Sig 63/T 15.2, Totenzettel für Frau Maria Catharina Simon aus dem Jahr 1697.

\section{Opracowania}

Aka Christine, Tot und vergessen? Sterbebilder als Zeugnis katholischen Totengedenkens, Detmold 1993.

Aschwanden Felix, Clauss Walter, Urner Mundart-Wörterbuch, Altdorf 1982.

Beer Manuel, Rehm Ulrich, Das kleine Andachtsbild. Graphik vom 16.zum 20. Jahrhundert, Georg Olms Verlag, Hildesheim 2004.

Boisdequin Michel, Les souvenirs mortuaires, à: Imagiers de paradis. Images de piété populaire du XVe au XXe siècle, Bastogne-Bruxelles 1990, p. 179-188.

Carl Marie-Luise, Totenzettel. Genealogische Quelle mit Geschichte, „Computergenealogie. Magazin für Familienforschung", 3 (2007) s. 19-21.

Christen Matthias, Die letzten Bilder: Tod, Erinnerung und Fotografie in der Zentralschweiz, Baden 2010.

Ciregna Elise Madeleine, Museums of Death, in: Encyclopedia of Death and the Human Experience, ed. C.D. Bryant, D.L. Peck, Los Angeles-London 2009, s. 765.

Demmel Fritz, Das Sterbebildchen- die letzte Visitenkarte, in: Das Mühlrad. Beiträge zur Geschichte des Inn- und Isengaues. Band XXXIII, Mühldorf 1991, s. 159-166.

Dufour Jean, Les rouleaux et encycliques mortuaires de Catalogne (1008-1102), „Cahiers de civilisation medieval”, 20 (1977) no 77, p. 13-14. 
Encyclopedia of Death and the Human Experience, ed. C.D. Bryant, D.L. Peck, Los Angeles-London 2009.

Engels Matthias T., Das kleine Andachtsbild. Prägedrucke und Stanzspitzenbilder des. 19. Jahrhunderts, Recklinghausen 1983.

Fischer Helmut, Rheinische Soldatentotenzettel, „Heimatblätter des Rhein-Sieg-Kreises”, 79 (2011) s. 134-147.

Fischer Helmut, Zum frommen Andenken. Biographisches Erzählen auf Totenzetteln, „Rheinisches Jahrbuch für Volkskunde”, 34 (2001/2002) s. 69.

Gärtner Hans, Andachtsbildchen: Kleinode privater Frömmigkeitskultur, München 2004.

Imfeld Karl, Obwaldner Mundart-Wörterbuch, Kriens 2000.

Jarkiewicz Katarzyna, Patriotyczne obrazki, „Posłaniec Serca Jezusowego”, 4 (2016) s. 54-56.

Jarkiewicz Katarzyna, Sakralność i profaniczność obrazka religijnego. Wokół problemów oddziaływania Kościoła na sferę wytwórczości dewocyjnej, w: Ponowoczesne przestrzenie oddziaływań wychowawczo-formacyjnych Kościoła i „ziemie niczyje”, red. R. Jasnos, E. Miśkowiec, Kraków 2015, s. 251-274.

Kapralska Łucja, Maksymowicz Agata, Śmierć w Internecie, w: Od robotnika do internauty. W kierunku społeczeństwa informacyjnego, red. A. Siwik, L.H. Haber, Kraków 2008, s. 309-320.

Kusiak Franciszek, Ze św. Franciszkiem z Asyżu poprzez śmierć cielesną do nieba na obrazkach z minionych wieków, Warszawa 2014.

Lesaar Bernhard F., Totenzettel - Sterbebildchen als Hilfsquellen für die Familienforschung, „Genealogie - Deutsche Zeitschrift für Familienkunde”, 4 (2008) s. 289-296.

Lietzmann Hans, Die Entstehung der Christlichen Liturgie nach den ältesten Quellen, „Vortrage der Bibliothek Warburg”, 5 (1929) s. 45-66.

Mielke Heinz-Peter, Gott zur Ehre. Zum Bildprogramm des Kunstverlages B. Kühlen in Mönchengladbach, in: Volkskultur - Geschichte - Region: Festschrift für Wolfgang Brückner zum 60. Geburstag (Quellen und Forschungen zur europäischen Ethnologie, Bd. 7), Hg. D. Harmening, E. Wimmer, Würzburg 1990, s. 475- 492.

Ollig Werner, Zum frommen Gedenken... Ein papierenes Epitataph. Der Totenzettel im Wandel der Zeit, Fürstenfeldbruck 2009.

Pernoud Régine, Les Saints au Moyen Âge: la sainteté d'hier est-elle pour aujourd'hui?, Paris 1984.

Pirotte Jean, Images des vivants et des morts: la vision du monde propagée par l'imagerie de la dévotion dans le Namurois (1840-1965), Bruxelles 1987.

Pirotte Jean, Les images de devotion du XV siecle a nos jours. Introduction a l'etiude d'en „media”, à: Imagiers de paradis. Images de piété populaire du XVe au XXe siècle, Bastogne-Bruxelles 1990, p. 11-13.

Rayski Stefan, Genjusz niepodległości, Lwów 1935.

Schwering Burkhard, Totenzettel. Zur Geschichte eines sepukralkulturellen Brauchrequisits, „Rheinisches Jahrbuch für Volkskunde”, 34 ( 2001/2002) s. 49-66.

Seifert Siegfried, Totenbildchen, in: Memento Mori - Gedenke des Todes - Erinnerung hilft. Totenbildchen. Sammlung Pfarrer Joachim Meckler, Hg. S. Seifert, J. Meckler, Schöntal Bieringen 1993.

Van den Bergh Karel, Bidprentjes in de zuidelijke Nederlanden, Brüssel 1975.

Verspaandonk J.A. J.M., Het hemels prentenboek. Devotie- en bidprentjes vanaf de 17e eeuw tot het begin van de 20e eeuw, Hilversum 1975.

Warlop Ernest, Maddens Niklaas, De nieuwe Stadsbibliotheek en het Arrondissementsdepot van het Rijksarchief te Kortrijk, ,Verslagen en mededelingen van de Leiegouw”, 6 (1964) nr 1, p. 265-271. 
Wunderlin Dominik, Das Leidhelgeli als Informationsträger und Erinnerungshilfe, in: Zum frommen Andenken. Leidhelgeli/Sterbebildchen in der Sammlung Dr. Edmund Müller, Hg. D. Wunderlin, Beromünster 2011, s. 35-49.

Zum frommen Andenken. Leidhelgeli/Sterbebildchen in der Sammlung Dr. Edmund Müller, Hg. D. Wunderlin, Beromünster 2011.

\title{
MEMORY SIGNS. THE COMMEMORATING FUNCTION OF RELIGIOUS PICTURES
}

\begin{abstract}
Summary
Shaped in the fifteenth century religious images in Baroque took commemorative figure corresponding to the specifics of Catholic funeral rites. It became a symbol of mourning leaflets imparting basic knowledge of deceased persons and inspiring prayers and memorial services. Mourners in the sense of religious obligation hid the souvenirs in the prayer books and drawers, pinned to the memory array or presented in other places. This process strengthened the experience of world wars that shaped the need to honor the soldiers' images. Secular heroes thus replaced Christ and the saints. Culture memory strengthened and included on the pictures secular content. Disappears need to care for the salvation of the living dead for mentioning them as relevant to our identity as people. This process intensifies the penetration of virtual reality memorabilia and development of the funeral culture.
\end{abstract}

Keywords: the culture of memory; the culture of death; holy card; funeral artifact; funeral iconography; the prayer for the dead 